\title{
A criança e o sótão
}

\begin{abstract}
Igor de Almeida Silva ${ }^{1}$
\section{Resumo}

Breve reflexão sobre recepção e pedagogia do teatro em contextos de mediação no espaço escolar, a partir de dois dossiês pedagógicos sobre os espetáculos Os Efêmeros (Les Éphémères) e Os Náufragos da Louca Esperança (Les Naufragés du Fol Espoir), direção de Ariane Mnouchkine, pelo Théâtre du Soleil.
\end{abstract}

Palavras-chave: mediação; pedagogia do teatro; dossiê pedagógico; Théâtre du Soleil

\section{Abstract}

Brief reflection on reception and theater pedagogy in contexts of mediation at school, based on two teaching dossiers prepared for the productions Les Éphémères and Les Naufragés du Fol Espoir, both directed by Ariane Mnouchkine, with the Théâtre du Soleil.

Keywords: mediation; theater pedagogy; teaching dossiers; Théâtre du Soleil

"Saber orientar-se numa cidade não significa muito. No entanto, perderse numa cidade, como alguém se perde numa floresta, requer instrução". Walter Benjamin (1995, p. 73).

Pièce (dé)montée [Peça (des)montada], coleção de dossiês pedagógicos sobre espetáculos em cartaz na cidade de Paris, concebida como ferramenta didática pelo Centro Regional de Documentação Pedagógica (CRDP) de Paris, com o apoio da Inspeção Geral Letras-Teatro e de Jean-Claude Lallias, conselheiro de Teatro no Centro Nacional de Documentação Pedagógica (CNDP). Estes dossiês são direcionados às aulas dos professores dos Liceus que promovem a ida de seus alunos ao teatro. Trata-se de uma modalidade de mediação artística na escola, no âmbito da pedagogia do teatro, voltada particularmente para o estímulo da fruição estética. De certa maneira, para a formação do espectador. Segundo o próprio site desta coleção (http://crdp.ac-paris.fr/piece-demontee/), seus objetivos são "Facilitar a compreensão dos elementos específicos que estão em jogo no teatro, confrontando os textos às

\footnotetext{
1 Igor de Almeida Silva possui mestrado em Letras pela UFPE e, atualmente, cursa o doutorado em Artes Cênicas na USP. É autor do livro Réquiem à infância: um estudo sobre Um sábado em 30 e Viva o cordão encarnado, de Luiz Marinho (Recife: Bagaço, 2009).
} 
suas configurações espaciais e vocais; analisar o texto teatral em suas relações com a representação" (Tradução nossa).

\section{Peça desmontada: Os Efêmeros}

O dossiê Os Efêmeros, preparado por Jean-Louis Cabet, com a colaboração de Béatrice Picon-Vallin e Jean-Claude Lallias, estrutura-se em duas partes. Na primeira, "Antes de ver o espetáculo" (Avant de voir le spectacle), em que a representação é oferecida aos alunos em aperitivo (la représentation en appétit), há diferentes materiais de trabalho para professores e estudantes, distribuídos em um ordenamento progressivo. De entrada, um "retrato" do Théâtre du Soleil, com biografia de Ariane Mnouchkine e cronologia do grupo. Em seguida, é reproduzido um trecho de um encontro de Mnouchkine com estudantes de liceus em Avignon, no Sul da França, em 2006, na época de lançamento do filme O Último Caravançará (Le Dernier Caravansérail). Também constam, nesta primeira parte, uma entrevista com a encenadora e algumas propostas de atividades a partir do programa, do título e de imagens do espetáculo.

Na segunda parte do dossiê, "Depois de ter visto o espetáculo" (Après avoir vu le spectacle), em que se oferecem agora "pistas de trabalho" (pistes de travail), seu eixo é basicamente a memória do aluno em torno do que foi assistido em cena. Se Os Efêmeros foi fecundado pelas memórias de seus artistas, o trabalho pedagógico centra-se na memória dos próprios estudantes acerca do espetáculo, buscando-se retomar em sala de aula vários aspectos da narrativa, do dispositivo cênico, dos objetos de cena, do jogo dos atores, da encenação de modo geral. Sugere-se, portanto, o espaço escolar como lugar de discussão e reflexão, de rememoração e compartilhamento da experiência sensível. Além disso, há ainda, nesta segunda parte do dossiê, uma alentada entrevista com o músico do espetáculo Jean-Jacques Lemêtre e um substancioso estudo da pesquisadora Béatrice Picon-Vallin. Ao final, são sugeridas outras referências literárias e teatrais que também tratam da memória e do cotidiano (por exemplo, peças e contos de Anton Tchékhov e poesias de Arthur Rimbaud e Pablo Neruda) como forma de continuidade e transbordamento desta experiência ao mesmo tempo estética e pedagógica.

Este dossiê é orgânico em sua orquestração, além de estar em harmonia com as propostas cênicas do espetáculo em questão. Toda sua primeira parte tem como foco o tema da memória, dos pequenos tesouros invisíveis do cotidiano e da brevidade da vida. Temáticas centrais do próprio espetáculo, abordados no dossiê de diferentes 
maneiras, desde a conversa de Mnouchkine com estudantes de Avignon, passando por texto de Marcel Proust em resposta a uma questão sobre o que ele faria se o mundo fosse acabar (este foi o mesmo mote que iniciou os ensaios de Os Efêmeros), até a entrevista da encenadora em que ela discorre sobre aspectos importantes da montagem e de suas temáticas veiculadas. A partir dessa contextualização, as atividades propostas, nessa primeira parte do dossiê, giram em torno desses mesmos temas. Por exemplo, são sugeridos jogos e dinâmicas nos quais os alunos tentariam responder por escrito a mesma pergunta dirigida a Marcel Proust, sendo as respostas compartilhadas posteriormente. Outro jogo, "contar uma lembrança vivida", inspirado no trabalho do ator e encenador Didier Lastère, codiretor do Théâtre de l'Éphémère.

Mais ao final dessa primeira parte propõem-se atividades em torno do programa, do título e de imagens do espetáculo, procurando estimular o aluno a formular indagações e hipóteses acerca do espetáculo, como se, antes de ir à récita, ele já tivesse uma representação imaginária, em busca do confronto criativo no qual ele iria confirmar ou reformular suas especulações iniciais. Estas atividades também são contextualizadas com imagens e intertextos, que vão de um trecho de O Pequeno Príncipe, de Antoine de Saint-Exupéry (no qual se compara a efemeridade de uma flor à eternidade de uma montanha) até a transcrição do verbete da palavra "Efêmero", disponível em Le Robert métodique.

\section{Peça desmontada: Os Náufragos da Louca Esperança}

No dossiê dos Náufragos da Louca Esperança, de autoria de Gaëlle Bebin, sua primeira parte, "Antes de ver o espetáculo", se divide em cinco sessões: na primeira, em torno do título e do tema dos "náufragos"; na segunda, sobre as questões do cinema no início do século; na terceira, sobre a literatura de Jules Verne; na quarta, a história europeia do final do século XIX e início do século XX, especificamente os fatos que servem de pano de fundo das narrativas de Os Náufragos da Louca Esperança e, por último, o próprio trabalho do Théâtre du Soleil. Na segunda parte, "Depois de ter visto o espetáculo", sua estrutura também se divide em cinco sessões: na primeira, "pistas de trabalho", abordando as particularidades do espaço, da Cartoucherie, do prólogo do espetáculo, do roteiro de contrarregragem (feuille de regie); na segunda, as relações entre as diferentes temporalidades do espetáculo e da criação da trupe; na terceira, relações da cenografia e do jogo dos atores com o cinema mudo; na quarta, sobre a música, e na quinta, novamente em torno do próprio Théâtre du Soleil, as relações 
do espetáculo com a história e o presente, semelhanças entre este espetáculo e os demais da trajetória do Soleil.

Apesar de aparentemente coerente em sua estrutura interna e semelhante ao dossiê sobre Os Efêmeros, todos esses tópicos do dossiê são desprovidos de uma significação e articulação próprias, de motivos e fins aos quais se destina e, sobretudo, de interconexões com o espetáculo que possam alimentar o desejo pelo teatro (Cf. PUPO, 2009). Detendo-se em cada atividade proposta, é difícil para o leitor compreender os princípios e as escolhas que nortearam o trabalho da autora, principalmente na primeira parte, "Antes de ver o espetáculo". São atividades aleatórias e artificiais. Parece que a autora se apoiou em tudo que parecia mais concreto, apreensível (ex: título e cartaz do espetáculo, resumos das obras de Jules Verne, fatos históricos, etc), sem despertar interesse ou vínculo do aluno por uma encenação ainda por acontecer. Sem contextualizar previamente as atividades propostas, transforma o espetáculo em um quebra-cabeça, a ser reestruturado, remontado, mas sem uma possibilidade efetiva de resignificação. Os textos e as imagens espalhados por todo o dossiê são mera decoração, sem possuir de fato uma função. Muito restrito ao texto e a uma visão compartimentada do conhecimento em arte.

$\mathrm{Na}$ segunda parte do dossiê, atenua-se esse aspecto. Suscita-se, de certa maneira, a memória do espectador (como no primeiro dossiê) sobre o espaço (a Cartoucherie), o prólogo, as constantes mutações da cena (roteiro de contrarregragem), as narrativas do espetáculo, a música e a cenografia. Além disso, há uma quantidade razoavelmente generosa de entrevistas e depoimentos dos artistas do espetáculo que enriquecem o dossiê. No entanto, tudo é pretexto para se propor "tarefas" aos alunos, cujos resultados já são previstos e exigidos pelo professor.

\section{O espectador e a especialização}

Que concepções de formação estes dossiês possuem? Quais as origens dessa prática de mediação na escola? Por que formar o espectador? Quais os fins dessa prática? Como formá-lo? Eis algumas questões que surgem diante destes dois dossiês.

Trata-se de uma concepção de pedagogia do espectador que procura formar uma espécie de espectador especialista, fornecendo-lhe informações acerca da peça enfocada que possibilitem uma compreensão/decodificação de seus códigos. Essas informações recaem sobre o tema abordado, o texto, certas particularidades da criação cênica e técnicas teatrais. Possivelmente, as origens dessa forma de mediação teatral se encon- 
tram nos anos 1960 e 1970, especificamente na França e na Bélgica, entre outros países, que consistiam em visitas de trupes teatrais nas escolas para propor atividades dramáticas às crianças, com o objetivo de formar os espectadores das gerações futuras. Nesse momento, essas práticas de mediação eram denominadas de animações teatrais.

Conforme Flávio Desgranges, existiam duas modalidades de animação: animações teatrais autônomas e animações teatrais periféricas. Esta última se estruturava em torno de um espetáculo específico e se concentrava basicamente no trabalho de fruição da obra teatral:

Elas se estruturavam tanto com base em atividades que forneciam informações complementares a respeito do espetáculo que seria visto pelos participantes, quanto pela aplicação de exercícios que, explorando a linguagem teatral, se destinavam a capacitar o espectador iniciante a uma leitura mais aguda da encenação. Eram também utilizadas para avaliar o grau de compreensão e interesse do público sobre o espetáculo em questão. As animações teatrais periféricas aconteciam antes ou depois da apresentação do espetáculo. As atividades propostas antes da peça tinham o intuito de preparar os alunos espectadores para a leitura da peça que seria vista e, quase sempre, sublinhavam algum aspecto artístico do espetáculo que, assim, poderiam ser mais bem observados pelos alunos no ato de recepção da obra. Essas animações, por vezes, ensinavam aos participantes o funcionamento de alguns artifícios e elementos de cena do espetáculo, tais como: utilização dos refletores, criação da sonoplastia, construção de determinados materiais cenográficos, etc. Com esse procedimento, os animadores queriam desmistificar a máquina teatral, estimulando os alunos a lançar um olhar distanciado, crítico, à encenação que seria posteriormente apresentada (DESGRANGES, 2003, p. 50-51).

As animações teatrais periféricas se dividiam ainda em três categorias: animações de integração escolar, animações de expressão e animações de leitura. Esta última procurava especificamente

[...] dinamizar a recepção do aluno-espectador, propondo atividades que possibilitassem uma leitura mais apurada da obra. Fichas pedagógicas, contendo informações sobre a peça e sugestões de atividades para serem aplicadas pelos professores, antes ou depois do espetáculo, também eram utilizadas pelos grupos teatrais que promoviam essas animações. Eram apresentadas em duas vertentes: animações de leitura horizontal, que procuravam destacar e pôr em debate o tema da peça, ressaltando o conteúdo veiculado pelo espetáculo; e animações de leitura transversal, que buscavam propor atividades que capacitassem os espectadores iniciantes a decodificar os signos que constituíam a encenação (DESGRANGES, 2003, p. 54).

O momento histórico, marcado pelo estruturalismo e pelo advento da semiologia do teatro na França, determina essa concepção pedagógica, seus procedimentos e objetivos de aprendizagem: uma tentativa de escapar da leitura imediata e espontânea da obra teatral, de não permitir que o espectador se fixasse apenas nos elementos da fábula, mas pudesse seguir pistas que o levassem para uma compreensão mais 
global do espetáculo; de fazê-lo perceber o discurso da encenação (ou texto cênico) para além da "mensagem" do texto dramático; de desnaturalizar a fruição da obra de arte, tornando-a um ato culturalmente construído e complexo. Resumindo: um espectador especialista. Estas parecem ser as origens, os meios e os fins encravados na concepção pedagógica destes dois dossiês.

\section{O espectador e a emancipação}

Mas será que se precisa realmente formar o espectador? Para se compreender a cena contemporânea, são necessárias explicações? Diante destes dossiês e da longa trajetória das formulações de suas concepções artísticas e pedagógicas, tais indagações são inevitáveis. No teatro, desde Meyerhold e principalmente com Brecht, a função do espectador diante do fenômeno teatral é substancialmente reformulada e valorizada. Um papel ativo diante da cena Ihe é conferido, em que seus sentidos e criticidade são chamados no processo de significação do espetáculo. Dessa maneira, há uma coautoria do sentido da obra em que esta apenas se constitui na medida em que ativa a subjetividade do espectador, sendo ao mesmo tempo única e plural. Pluralidade e autoria que são radicalizadas a partir da pós-modernidade, em que o espectador torna-se o sujeito/ protagonista do acontecimento artístico. Não se trata apenas de conferir um sentido àquela obra, mas escrevê-la e reescrevê-la infinitamente, num trabalho de Sísifo, no qual, muitas vezes, a constituição de um ou vários sentidos não é a grande questão a ser respondida. A experiência sensível torna-se um labirinto para o qual o grande prazer é perder-se; olhar uma, duas, três vezes... e não reconhecer, estranhar... indagar!

Ao se enfatizar a ideia de formação, de provimento de instrumental de análise do espetáculo ao espectador iniciante e, sobretudo, de explicitação da obra de arte, como se pode inferir nos dois dossiês em questão (muito mais no segundo do que no primeiro), confere-se um caráter demasiado diretivo à fruição estética do aluno. Configura o processo pedagógico como um ato autoritário, que não parte da igualdade de inteligências, mas de sua desigualdade. E sua tentativa de atenuar essa distância provoca um efeito contrário. Ao invés de emancipar o espectador, torna-o cada vez mais dependente de uma explicação. Penso em Benjamin, no seu ensaio "O Narrador" (1994); penso também em Rancière, no livro O Mestre Ignorante (2002) e no ensaio "O Espectador Emancipado" (2010). Em ambos, a necessidade de explicações é questionada. Benjamin diz: 
[...] quase nada do que acontece está a serviço da narrativa, e quase tudo está a serviço da informação. Metade da arte narrativa está em evitar explicações. [...] O extraordinário e o miraculoso são narrados com a maior exatidão, mas o contexto psicológico da ação não é imposto ao leitor. Ele é livre para interpretar a história como quiser, e com isso o episódio narrado atinge uma amplitude que não existe na informação (1994, p. 203).

Já Rancière: "É o explicador que tem necessidade do incapaz, e não o contrário, é ele que constitui o incapaz como tal. Explicar alguma coisa a alguém é, antes de mais nada, demonstrar-lhe que não pode compreendê-lo sozinho" (2002, p. 20). Nesse caso, a explicação é a negação da possibilidade de o espectador ter acesso a sua inteligência e subjetividade e, a partir delas, estabelecer suas próprias conexões, associações ou dissociações que permitem criar por si mesmo possíveis leituras do espetáculo, sua compreensão pessoal e única, que não deixa também de ser um processo de construção de conhecimento em teatro, sem esperar a autorização do "discurso competente", "autorizado", mas pressupondo, nas palavras de Rancière, a igualdade de inteligências.

Nesse sentido, até que ponto, nestes dossiês, há uma perspectiva de se trabaIhar com questões menos explícitas, mais ligadas à subjetividade, ao inconsciente dos alunos, de modo não diretivo?

No segundo dossiê, sobre Os Náufragos da Louca Esperança, a perspectiva é mínima. E, mesmo quando se tenta estabelecer uma abertura para a concepção de mundo dos alunos, esta se dá de modo desconexo. No começo do dossiê, antes dos alunos assistirem ao espetáculo, como forma de discutir seu tema e título, surge a pergunta: "Qual seria hoje sua louca esperança?" E a autora Gaëlle Bebin não dá prosseguimento, logo ela passa para uma atividade diferente, que é catalogar obras literárias que tratam do tema do naufrágio. A autora tenta compartimentar racionalmente toda forma de conhecimento sensível. Como blocos etiquetados, manufaturados, prontos para exportação. Neste caso, a perspectiva de formação de um espectador especialista demonstra ser problemática. É sempre necessário um conhecimento externo para que se possa fruir a obra de arte? É preciso tornar o público um especialista?

Essas questões são relativizadas no primeiro dossiê, sobre o espetáculo Os Efêmeros, de autoria de Jean-Louis Cabet. Aqui, a subjetividade dos alunos é amplamente estimulada, sem deixar de lado os conhecimentos específicos em teatro. De um lado, possibilita-se o acesso do aluno à sua experiência cotidiana e pessoal em uma leitura particular do espetáculo; de outro, não lhe é renegado o conhecimento vertical da área (e da peça em questão), por meio de entrevistas com os artistas envolvidos, 
comentários e notas perspicazes e bem fundamentados de Cabet, e da arguição de especialistas (no caso, o ensaio de Béatrice Picon-Vallin).

Percebem-se concepções díspares de formação em teatro nos dois dossiês. $O$ dossiê sobre Os Náufragos, fundado em uma educação depositária, tendendo ao embrutecimento, no dizer de Rancière; o outro, sobre Os Efêmeros, finca-se em perspectivas mais amplas e flexíveis que tendem a friccionar e relativizar as duas modalidades de espectador discutidas neste ensaio: o especialista e o emancipado. No dossiê de Os Efêmeros, há um conhecimento a ser construído sim; porém, o seu fim não é completamente premeditado ou controlado pelo professor, pois é dada ao aprendiz a liberdade de empregar sua própria inteligência, gerando algo outro ao que o professor já sabe e revelando a si mesmo seu poder intelectual. Aqui, o que impera então é a concepção de formação como modo de colocar o espectador diante de diferentes experiências estéticas, proporcionando espaços de troca e discussão, em busca da construção de um conhecimento coletivo e individual (de acordo com cada subjetividade), sem perder de vista a ideia de uma aprendizagem especializada em teatro.

\section{O espectador e a utopia}

Uma proposta pedagógica de mediação teatral deveria estar em comunhão ou diálogo com a proposição artística do grupo ou espetáculo em questão?

Em suas entrevistas, Mnouchkine sempre faz referência aos seus processos de criação e aos espetáculos do Théâtre du Soleil como um retorno à infância, uma viagem ao maravilhoso, uma aventura, uma utopia. E, no que concerne ao público, ela diz: "Nós mesmos, nós devemos ser os viajantes que conduzem o público em viagem e em exploração interior, ao interior de vidas, de nossas semelhanças" (2009, p. 39, tradução nossa). Este princípio parece ter sido seguido exemplarmente por Jean-Louis Cabet em seu dossiê sobre Os Efêmeros. Encandeadas de modo coerente e sensível, as atividades do dossiê propostas aos alunos não se fecham em si mesmas. Pelo contrário, abrem-se à sensibilidade, à inteligência e à imaginação, associando os processos de criação do grupo ao ato de fruição estética dos alunos-espectadores. Em outras palavras: o autor retoma os mesmos princípios que nortearam a criação do espetáculo, elegendo a memória, os mundos íntimos da subjetividade humana, como matéria-prima de seu dossiê.

No entanto, em nenhum momento, o dossiê sobre Os Náufragos possibilitou uma viagem semelhante. As atividades e informações fornecidas mais confundem do que 
permitem uma primeira abordagem do espetáculo. Os materiais que serviram à criação do Soleil (obra de Jules Verne, filmes do cinema mudo, contexto histórico) são oferecidos em fragmentos, descontextualizados, sem que os alunos tenham o tempo necessário para reconhecê-los, apreciá-los, explorá-los, descobri-los, como fez o Théâtre du Soleil na criação do espetáculo. Isto é perceptível pela sua própria configuração e pela quantidade excessiva de atividades, muitas vezes sem interligação ou propósito aparente.

A ideia de viagem e de aventura que caracteriza os espetáculos do Soleil e sua relação com o público poderia não apenas estar presente neste dossiê, mas também servir de inspiração no trabalho de mediação de modo geral. De certa maneira, ela está presente no dossiê anterior, sobre Os Efêmeros. Ou seja, a mediação teatral deve ser também uma viagem ou uma aventura rumo ao imaginário, ao desconhecido, assim como é o teatro. Seria isso uma utopia? Como nutri-la então?

Utopia é uma palavra recorrente no vocabulário de Mnouchkine, além de ser uma palavra bastante significativa para se referir ao espetáculo Os Náufragos da Louca Esperança: às vésperas da 1ำ Guerra Mundial, um grupo de artistas decide realizar um filme de "educação e recreação popular" no sótão da guinguette "A Louca Esperança". Metáfora esta da trajetória e dos ideais do próprio Soleil. Mas o que significa a palavra utopia? Mnouchkine possui sua própria definição:

\footnotetext{
Eu li recentemente uma definição de utopia que enfim me satisfez, porque cada vez que se fala de utopia, é ultrapassado, é o sonho impossível... Mas esta definição [...] me convém: 'Utopia é o possível ainda não realizado [...]. Quando nós, meus amigos e eu, fundamos a trupe, e mesmo já um pouco antes, nós tínhamos uma utopia. Eu digo sempre que nós fundamos o Théâtre du Soleil para sermos felizes (2009, p. 21, tradução nossa).
}

Infância é outra palavra solar no vocabulário da trupe francesa. A infância é como a encenadora sintetiza em uma palavra e imagem as qualidades que ela exige de seus atores e os efeitos que pretende provocar no público, supõe-se: um retorno à infância. Ou seja, a capacidade de se encantar e acreditar realmente no que se passa sobre o palco:

Vê-se bem que na pesquisa teatral, quando os atores, as atrizes estão
realmente onde devem estar, quer dizer, na infância verdadeiramente, em uma
imaginação que é uma imaginação física - não uma imaginação intelectual
-, uma verdadeira imaginação, isto tudo torna-se uma encarnação. É uma
invocação. E a verdade vem (MNOUCHKINE, 2009, p. 41-42, tradução nossa).

E essa volta ao tempo infantil é também descer ao sótão: retornar a um lugar de recordação, rico de informações, de memória e de fantasia: "Falava-se de infância há pouco, mas é verdade que os atores devem ter à sua disposição como que um imenso sótão, onde cada um pode procurar coisas para se fantasiar”' (2009, p. 60, tradução nossa). 
Em Os Efêmeros, há quase sempre uma criança em cena, que dirige um olhar particular ao passado. São adultos que retornam à época da infância. $E$, aqui, ser criança ou voltar a ser criança representa a imagem cênica da procura e do entendimento: de si mesmo, do outro, do que se desconhece. Já em Os Náufragos, toda a sua narrativa se passa em um grande sótão, tornando história e experiência suas grandes protagonistas. E a voz do gravador que é acionado no início do espetáculo (res)soa em cena "como o estalar do graveto seco ao ser pisado" (BENJAMIN, 1995, p. 71). O espectador é a criança que se perde nas ruelas de uma grande cidade, o espetáculo. Mas este, de quando em vez, libera alguns gravetos, cujo estalar liberta a criança (o espectador) de qualquer temor ao desconhecido, fazendo-a imergir em seu sótão, em novas aventuras exploratórias.

Benjamin, nos seus ensaios sobre a infância, compara o seu olhar (o da criança) ao do artista ou ao do colecionador. No primeiro, esta inventa possibilidades; no segundo, é um olhar que dedica ao objeto uma afetividade, buscando-Ihe sua experiência, suas histórias. E, ao lidar com o brinquedo, desmontando-o e reconstruindo-o, a criança estabelece uma relação afetiva e íntima com ele, resignificando-o à sua maneira, tal como um espectador emancipado, na acepção de Rancière.

Esta concepção do olhar infantil também parece similar à de Mnouchkine quando ela fala da utopia, da infância e do sótão na poética de seu teatro e no trabalho do ator. Também não seria esta uma característica que ela procura estimular, e mesmo solicitar do espectador? Como alimentar a utopia? Como despertar o nosso olhar infantil, que é pleno de possibilidades ainda não concretizadas, diante do espetáculo? Como mediar o desabrochar do olhar infantil do espectador diante da cena? Como descer ao sótão?

Discutindo o ensaio autobiográfico "Infância em Berlim por volta de 1900", de Walter Benjamin, Jeanne Marie Gagnebin faz a seguinte afirmação: "No limiar do labirinto, a criança não manifesta medo; pelo contrário, o desejo de exploração predomina como se soubesse, confusamente, que só poderá se reencontrar se ousar perder-se" (2004, p. 91). Talvez seja esta uma bela imagem para uma pedagogia do espectador: o desejo de exploração em que não se teme perder a si mesmo, pois apenas assim é possível reencontrar-se na cena, com uma imaginação disponível, similar à das crianças, permitindo-se ver, acreditar, sentir, indo para além dos limites, à procura do possível ainda não realizado. Descer ao sótão. Mas, para isso, é necessário instrução, ou melhor, mediação.

Rancière e Mnouchkine falam de modo semelhante. Ambos pressupõem um mesmo espectador. No entanto, o filósofo nos oferece conceitos e a encenadora imagens. 
A criança: o retorno à infância, como estado de prontidão e abertura, ponto de partida que pressupõe a igualdade de inteligências. O sótão: o voltar-se a si mesmo, lugar de recordação e criação. Utopia: emancipação. O pensamento independente, o possível não realizado ainda.

A criança e o sótão: utopia. Uma alquimia para uma possível pedagogia do teatro, em que ser criança é voltar ao sótão: "Eu digo frequentemente que os atores colocam suas máscaras, enquanto que o público retira a sua, quer dizer, suas tensões, e que ele se prepara para este momento que é uma utopia, onde 600 pessoas vão viver juntas" (MNOUCHKINE, 2009, p. 67-68, tradução nossa).

\section{Referências Bibliográficas}

BEBIN, Gaële. Piéce (dé)montéé - Dossier pédagogique du spectacle Les Naufragés du Fol Espoir (Aurores). Paris: CRSP/Académie de Paris, n. 101, jan. 2010. Disponível em: http:// crdp.ac-paris.fr/piece-demontee/piece/index.php?id=les-naufrages-du-fol-espoir

BENJAMIN, Walter. O narrador. Considerações sobre a obra de Nikolai Leskov. In:

Magia e técnica, arte e política: ensaios sobre literatura e história da cultura. Trad. Sérgio Paulo Rouanet. Prefácio Jeanne Marie Gagnebin. 7. ed. São Paulo: Brasiliense, 1994, p. 197221. (Obras escolhidas, vol. 1).

Infância em Berlim por volta de 1900. In:

Rua de mão única. 5. ed. Trad. Rubens Rodrigues Torres Filho e José Carlos Martins Barbosa. São Paulo: Brasiliense, 1995, p. 71-142. (Obras escolhidas, vol. 2).

CABET, Jean-Louis. Piéce (dé)montéé - Dossier pédagogique du spectacle Les Éphémères. Paris: CRSP/Académie de Paris, n. 26, jan. 2007. Disponível em: http://crdp.ac-paris.fr/piecedemontee/piece/index.php?id=les-ephemeres

DESGRANGES, Flávio. A pedagogia do espectador. São Paulo: Hucitec, 2003.

GAGNEBIN, Jeanne Marie. História e narração em Walter Benjamin. 2. ed. São Paulo: Perspectiva, 2004.

Ariane Mnouchkine. Introduction, choix et présentation des textes par Béatrice PiconValin. Paris: Actes Sud-Papiers, 2009.

PUPO, Maria Lúcia de Souza Barros. Para alimentar o desejo de teatro. Sala Preta, São Paulo, Programa de Pós-Graduação em Artes Cênicas, Universidade de São Paulo, n. 9, p. 269-278, 2009.

Mediação artística, uma tessitura em processo. Urdimento, Florianópolis, Programa de Pós-Graduação em Teatro, Universidade do Estado de Santa Catarina, n. 17, p. 113-121, 2011.

RANCIÈRE, Jacques. O mestre ignorante: cinco lições sobre a emancipação intelectual. Trad. Lilian do Valle. Belo Horizonte: Autêntica 2002.

O espectador emancipado. Trad. Daniele Ávila. Urdimento, Florianópolis, Programa de Pós-Graduação em Teatro, Universidade do Estado de Santa Catarina, vol. 1, n. 15, p. 107-122, out. 2010. 